\title{
Effects of a combined treatment regimen consisting of Hsp90 inhibitor DS-2248 and radiation in vitro and in a tumor mouse model
}

\author{
Takuhito Kondo $^{1 \wedge}$, Yuta Shibamoto ${ }^{\wedge}$, Tatsuya Kawai ${ }^{1 \wedge}$, Chikao Sugie $^{1}$, Zhen Wang $^{1}$, Koichi Nakamura $^{2}$, \\ Taro Murai ${ }^{1}$, Yoshihiko Manabe ${ }^{1} \wedge$, Masahiro Nakashima ${ }^{1}$, Masayuki Matsuo $^{3}$ \\ ${ }^{1}$ Department of Radiology, Nagoya City University Graduate School of Medical Sciences, Aichi, Japan; ${ }^{2}$ Drug Metabolism \& Pharmacokinetics \\ Research Laboratories, Daiichi-Sankyo Co., Ltd., Tokyo, Japan; ${ }^{3}$ Department of Radiology, Gifu University School of Medicine, Gifu, Japan \\ Contributions: (I) Conception and design: T Kondo, Y Shibamoto, T Kawai, C Sugie; (II) Administrative support: C Sugie, Z Wang, T Murai, Y \\ Manabe, M Nakashima, M Matsuo; (III) Provision of study materials or patients: T Kondo, K Nakamura; (IV) Collection and assembly of data: T \\ Kondo; (V) Data analysis and interpretation: T Kondo, Y Shibamoto; (VI) Manuscript writing: All authors; (VII) Final approval of manuscript: All \\ authors. \\ Correspondence to: Takuhito Kondo, MD. Department of Radiology, Nagoya City University Graduate School of Medical Sciences, 1 Kawasumi, \\ Mizuho-cho, Mizuho-ku, Nagoya 467-8601, Japan. Email: takt0826@gmail.com.
}

Background: Heat shock protein 90 (HSP90) is a molecular chaperone that is responsible for the conformational maintenance of several client proteins that play important roles in DNA damage repair, apoptosis following radiation, and resistance to radiation therapy. DS-2248 (tricyclic pyrazolopyrimidine derivative) is a newly-developed, orally available inhibitor of HSP90 with low adverse effects. We investigated the combined effects of radiation and DS-2248 in vitro and in vivo.

Methods: SCCVII squamous cell carcinoma cells and tumors transplanted in $\mathrm{C} 3 \mathrm{H} / \mathrm{HeN}$ mice were used. In vitro combined effects of X-ray radiation and DS-2248 were investigated using a colony assay. Phosphorylated histone $\mathrm{H} 2 \mathrm{AX}(\gamma \mathrm{H} 2 \mathrm{AX})$ was quantified after 2-Gy irradiation with or without 24-hour pretreatment with DS-2248. The mice bearing SCCVII tumors received oral DS-2248 10 times over 2 weeks and received local irradiation with doses of 1, 2, 3, and 4 Gy delivered 6 times over 2 weeks. Then, tumor volumes were measured.

Results: Radiation plus pretreatment with $50 \mathrm{nM}$ DS-2248 for 24 hours produced synergistic effects on SCCVII cells. $\gamma \mathrm{H} 2 \mathrm{AX}$ foci persisted after radiation for longer periods (6 and 24 hours) in DS-2248-treated cells than in control cells. In vivo, the combined effects appeared to be additive when 5 or $10 \mathrm{mg} / \mathrm{kg}$ DS2248 was combined with total radiation doses of 6-18 Gy, but the effect was considered supra-additive when $15 \mathrm{mg} / \mathrm{kg}$ of DS-2248 was combined with a total dose of $24 \mathrm{~Gy}$.

Conclusions: The combined effects of DS-2248 and radiation were additive at low drug and radiation doses, but may have been supra-additive at higher doses. Inhibition of slow repair of DNA double strand breaks (i.e., homologous recombination) was considered to contribute to this combined effect.

Keywords: Radiation therapy; Hsp90 inhibitor; DS-2248; DNA-double-strand break; radiosensitizer

Submitted Feb 28, 2021. Accepted for publication May 06, 2021.

doi: $10.21037 /$ tcr-21-71

View this article at: https://dx.doi.org/10.21037/tcr-21-71

^ ORCID: Takuhito Kondo, 0000-0001-6878-1470; Yuta Shibamoto, 0000-0003-4255-8611; Tatsuya Kawai, 0000-0003-2572-3304; Chikao Sugie, 0000-0002-4147-0610; Yoshihiko Manabe, 0000-0001-6353-4315. 


\section{Introduction}

Squamous cell carcinomas (SCC) are relatively radiosensitive, and early SCC can be cured by radiation alone; however, advanced SCC are often difficult to cure by radiation alone, and strategies to sensitize tumors to radiation or enhance antitumor effects of radiation are necessary to control large SCC. As one of these strategies, inhibiting heat shock protein 90 (HSP90) seems to be attracting attention $(1,2)$. Several HSP90 inhibitors are now in clinical studies as anticancer agents (3-5). In addition, the possibility of their role as radiosensitizers has also been proposed in laboratory studies (2).

HSP90 is a molecular chaperone that assists in conformational maturation, folding, and refolding of client proteins during stress, and protects them from degradation. Over 200 client proteins covering the vast majority of cellular processes, such as cell growth, proliferation, and survival, have been identified so far including tyrosine kinases, transcription factors, structural proteins, and hormone receptors (6-8). Inhibiting HSP90 reduces the function of these client proteins, leading to anti-tumor effects thereby increasing DNA double strand break (DSB) (9). In addition, since HSP90 plays a crucial role in establishing resistance to radiotherapy, inhibiting HSP90 is considered to sensitize tumors to radiation $(2,10)$, resulting in tumor growth suppression and augmentation of therapeutic cell death induction. One possible reason for radiosensitization may be inhibition of DNA DSB repair $(11,12)$.

Some of the newly-developed HSP90 inhibitors currently in clinical trials exhibit hepatic, pulmonary, cardiac, renal, and ocular toxicities, hindering their clinical use (13-15). Therefore, development of clinically acceptable HSP90 inhibitors for combination with radiation may be important for improving the results of radiation therapy. A tricyclic pyrazolopyrimidine derivative, DS-2248 (Figure 1), is a newly-developed fully synthetic and bioavailable HSP90 inhibitor developed by Daiichi-Sankyo Co., Ltd. (Tokyo, Japan). It is orally available and has shown potent activity in preclinical studies as an anticancer agent (16). DS2248 at $20 \mathrm{mg} / \mathrm{kg}$ had more potent anti-tumor effect than 17-allylamino-17-demethoxygeldanamycin (17-AAG, tanespimycin) at $50 \mathrm{mg} / \mathrm{kg}$ against NCI-N87 gastric cancer transplanted in nude mice (Honma et al., presented at 7 th International Conference on the Hsp90 Chaperone Machine, Seeon Abbey, Germany, October 15-19, 2014).
A pharmacokinetic study in Balb/c male mice showed an area under the curve at $0-8$ hours of $527 \pm 121 \mathrm{ng}$.hour $/ \mathrm{mL}$, maximum concentration in serum of $147 \pm 21 \mathrm{ng} / \mathrm{mL}$, and time to maximum concentration of $1.17 \pm 0.76$ hours after oral administration of $5 \mathrm{mg} / \mathrm{kg}$ DS-2248 (Daiichi-Sankyo, unpublished data). DS-2248 has also demonstrated activity in a Phase I trial in patients with advanced solid cancers (https://clinicaltrials.gov/ct2/show/NCT01288430). While preliminary clinical studies of this compound showed encouraging results, preclinical laboratory data are lacking with respect to their effects when combined with radiation. Therefore, in the current study, we investigated the effects of DS-2248 in murine SCC cells and tumors, either alone or in combination with radiation. The effects on DNA DSB were also investigated. We present the following article in accordance with the ARRIVE reporting checklist (available at https://dx.doi.org/10.21037/tcr-21-71).

\section{Methods}

\section{Tumor cells, mice, and drugs}

SCCVII, a murine SCC line that spontaneously arose in C3H mice, was used $(17,18)$; this was a gift from Kyoto University (Professor Koji Ono), where short tandem repeat analysis and mycoplasma testing were carried out before the transfer to our laboratory. Before initiation of this study, absence of mycoplasma infection was again confirmed. For in vivo studies, 8-week-old female C3H/ HeN mice were obtained from Nihon SLC Co. Ltd. (Hamamatsu, Japan) and were bred under semi-sterilized conditions. Characteristics of the cells and in vivo tumors have been previously described in detail $(17,18)$. SCCVII cells were cultured in a humidified atmosphere of $95 \%$ air $/ 5 \% \mathrm{CO}_{2}$ at $37{ }^{\circ} \mathrm{C}$ with Eagle's minimum essential medium supplemented with $12.5 \%$ fetal bovine serum. All animal experiments were performed under a project license (NO.: H29M-09) granted by the Animal Ethics Committee of Nagoya City University, in compliance with Japanese Fundamental Guidelines for Proper Conduct of Animal Experiment and Related Activities in Academic Research.

DS-2248 provided by Daiichi-Sankyo Co., Ltd. was dissolved in dimethylsulfoxide (DMSO) at a concentration of $50 \mu \mathrm{M}$ and then diluted with medium to $500 \mathrm{nM}$ for in vitro studies. For quantification of phosphorylated histone H2AX $(\gamma \mathrm{H} 2 \mathrm{AX})$, etoposide (OxiSelect DNA DSB Staining Kit; Cell Biolabs, Inc., SanDiego, CA, USA) dissolved in 


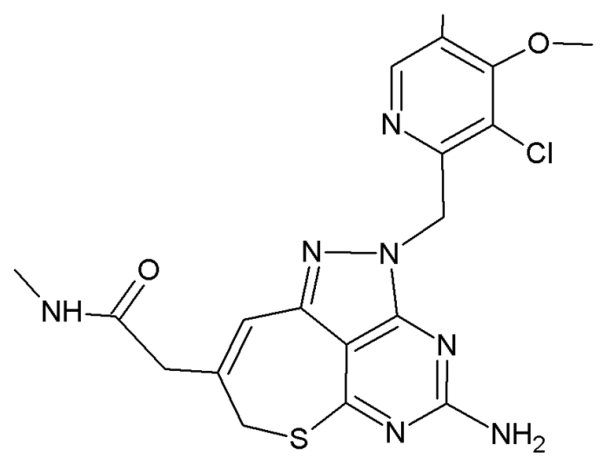

Figure 1 Chemical structure of DS-2248.

methanol at $20 \mathrm{mM}$ was used as a positive control. For oral administration in vivo, the drug was dissolved in $0.1 \mathrm{~N} \mathrm{HCl}$ in $0.5 \%$ methyl cellulose, and then the concentration was adjusted to $0.5,1.0$, and $1.5 \mathrm{mg} / \mathrm{mL}$ for the DS-2248 dose of 5,10 , and $15 \mathrm{mg} / \mathrm{kg}$, respectively, by adding $0.5 \%$ methyl cellulose. To guarantee that all mice received the same dose, DS-2248 was administered by a single investigator (TK) and all mice received the solution at $0.01 \mathrm{~mL} / \mathrm{g}$. The concentrations and drug doses tested in the present study were determined based on the preliminary studies conducted by Daiichi-Sankyo (data not shown).

\section{Treatment and colony formation assay}

Exponentially growing SCCVII cells were plated onto 6-cm plastic dishes with the following cell numbers: 150 for 0 Gy, 200 for 2 Gy, 500 for 4 Gy, 2,000 for 6 Gy, 20,000 for 8 Gy, 150 for DS-2248 + 0 Gy, 300 for DS + 2 Gy, 1,000 for DS + 4 Gy, 10,000 for DS + 6 Gy, and 120,000 for DS + 8 Gy. They were pre-treated with 50 nM DS-2248 dissolved in DMSO or the same concentration of DMSO alone for 24 hours at $37^{\circ} \mathrm{C}$. Then, the cells were irradiated at 2-, 4-, 6-, or 8-Gy doses at a dose rate of $1.6 \mathrm{~Gy} /$ minute with an X-ray apparatus CAX-210 (Chubu Medical Co., Ltd., Yokkaichi, Japan; 210 kVp, 10 mA, 2-mm Al filter) as previously described in detail (19). After irradiation, the culture medium was replaced with a fresh one without DS2248 , and cell survival was obtained by a colony formation assay; cell surviving fraction was determined from the plating efficiency of cells undergoing DS-2248 and/or radiation treatment divided by the plating efficiency of control (0 Gy) cells. Colonies containing 50 or more cells were stained and counted 7 days later.

\section{Quantification of $\gamma \mathrm{H} 2 A X$ foci per nucleus}

Our method for $\gamma \mathrm{H} 2 \mathrm{AX}$ foci quantification has been previously described in detail (20). Briefly, SCCVII cells were grown on 96-well chamber slides and treated with 25 or $50 \mathrm{nM}$ DS-2248 dissolved in DMSO, the same amount of DMSO alone, or etoposide at $100 \mu \mathrm{M}$ for 24 hours. Then, the cells were irradiated at 2 Gy using the CAX-210 X-ray machine. After irradiation, the culture medium was replaced with a fresh one without the drug. At 1, 6, and 24 hours after irradiation at 2 Gy or without irradiation, all groups of cells were fixed with $3.7 \%$ formaldehyde, permeabilized in $90 \%$ methanol, and blocked with $1 \%$ blocking/antibody incubation buffer (1\% bovine serum albumin/phosphatebuffered saline). The cells were then stained and mounted with 4',6-diamidino-2-phenylindole (DAPI; Thermo Scientific, Waltham, MA, USA), and $\gamma \mathrm{H} 2 \mathrm{AX}$ foci were detected with the primary antibody anti-phospho-histone H2AX ( $\times 100$, Ser 139, OxiSelect DNA DSB Staining Kit; Cell Biolabs, Inc.) and the secondary antibody fluorescein isothiocyanate-conjugated goat antimouse IgG antibody ( $\times 100$, OxiSelect DNA DSB Staining Kit). The $\gamma \mathrm{H} 2 \mathrm{AX}$ foci in at least 100 cells in each group were scored using IN Cell Analyzer 6000 (GE Healthcare UK Ltd., Little Chalfont, UK).

\section{Mouse model}

Exponentially growing cultured SCCVII tumor cells $\left(4 \times 10^{5}\right.$ cells $)$ were transplanted subcutaneously into the right hind legs of 9-week-old female $\mathrm{C} 3 \mathrm{H} / \mathrm{HeN}$ mice. Experiments were performed when the tumors reached $7 \pm 1 \mathrm{~mm}$ in maximum diameter. The tumor-bearing mice were randomly allocated to various treatment groups, and after measuring their tumor sizes, some of the mice were exchanged so that the average tumor volumes in all groups became similar.

First, three doses of DS-2248 dissolved in methyl cellulose were tested in combination with fractionated irradiation. Simulating the clinical situation, 5,10 , or $15 \mathrm{mg} / \mathrm{kg}$ of DS-2248 was administered orally for 5 consecutive days (Monday through Friday) over 2 weeks (i.e., days 1-5 and 8-12). A radiation dose of 4 Gy was delivered 3 times a week over 2 weeks (days 2, 4, 6, 9, 11, and 13) using the method described previously $(21,22)$. On the day of irradiation, DS-2248 was administered 6 hours before irradiation. This timing was used based on 


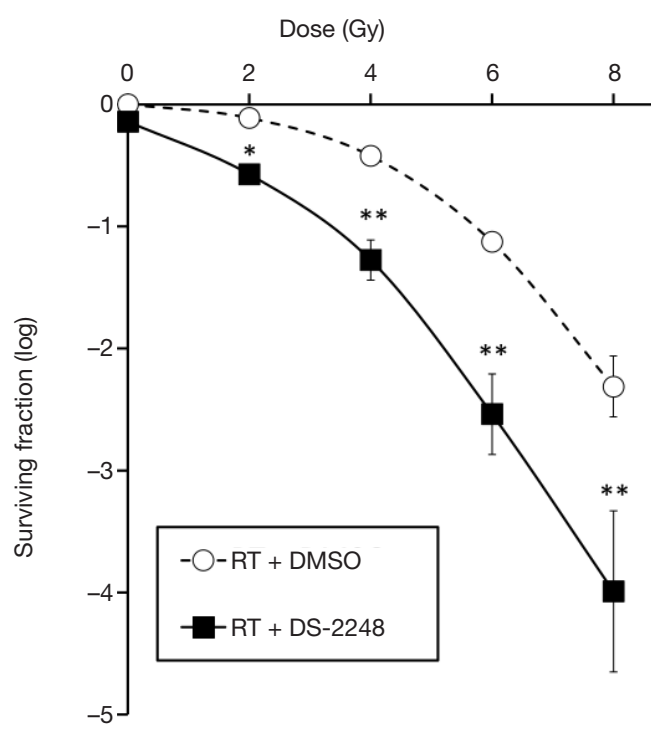

Figure 2 Radiation dose-survival curves obtained by a colony assay for SCCVII cells pretreated for 24 hours with $50 \mathrm{nM}$ DS-2248 (-) or dimethyl sulfoxide alone (DMSO; ०). Three experiments were performed for each point and bars represent standard errors. Regarding whether the combined effect was supra-additive or additive, ${ }^{*} \mathrm{P}=0.0001,{ }^{* *} \mathrm{P}<0.0001$ by post hoc Tukey's HSD (honestly significant difference) test.

the pharmacokinetic data showing that the concentration in tumors was maximal at 6 hours after oral administration $(15,16)$ and also to avoid any radioprotective effect caused by oral vehicle administration (23). The counterpart groups of mice received oral vehicle (methyl cellulose) administration with the same schedules. In the next experiments, $15 \mathrm{mg} / \mathrm{kg}$ of DS-2248 was combined with a fractional dose of 1, 2, or 3 Gy. The administration schedules for DS-2248 were identical to those of the first experiment.

Tumor volumes and body weights of the mice were measured 3 times per week for approximately 6 weeks. The three dimensions of the tumors were measured every other day using a caliper, and the tumor volume was defined as $\mathrm{V}=\pi / 6 \times$ products of the three dimensions, as previously described $(21,22)$.

Using Western blotting, HSP70 upregulation in SCCVII tumors by treatment with DS-2248 with or without irradiation was evaluated. Four groups of $\mathrm{C} 3 \mathrm{H} / \mathrm{HeN}$ mice bearing 7-mm SCCVII tumors were treated with the vehicle alone (10 times over 2 weeks), vehicle plus $4 \mathrm{~Gy} \times 6$ fractions over 2 weeks, DS-2248 $(15 \mathrm{mg} / \mathrm{kg}) \times 10$ times over 2 weeks, and the same DS-2248 plus radiation, respectively ( $\mathrm{n}=2$ for each group). The tumors were excised 24 hours later, and tumor allografts were solubilized with Cell Lysis Buffer (Cell Signaling Technology, Massachusetts, USA) containing cOmplete ${ }^{\mathrm{TM}}$ Mini Protease Inhibitor Cocktail (F. Hoffmann-La Roche, Ltd., Basel, Switzerland) and PhosSTOP ${ }^{\mathrm{TM}}$ Phosphatase Inhibitor Cocktail (F. Hoffmann-La Roche). Tumor lysates were resolved by $10 \%$ SDS-PAGE (sodium dodecyl sulfate polyacrylamide gel electrophoresis; DRC, Tokyo, Japan), transferred to a nitrocellulose membrane, and probed with Hsp70 antibody (SPA-810; Enzo Life Sciences, Inc., Lausen, Switzerland).

\section{Statistical analysis}

All data are shown as mean \pm standard error (SE). $\mathrm{P}$ value $<0.05$ was considered to indicate statistical significance. $\mathrm{R}$ Version 3.5.3 (The R Foundation for Statistical Computing, Vienna, Austria) was used to carry out statistical analyses. Differences in the $\gamma \mathrm{H} 2 \mathrm{AX}$ scores between groups were examined by $t$-test. To evaluate whether the combined effects of radiation and DS-2248 in vitro and in vivo were additive, supra-additive (synergistic), or sub-additive, a twoway factorial ANOVA (analysis of covariance) followed by post hoc Tukey's HSD (honestly significant difference) test implemented in $\mathrm{R}$ was used; $\mathrm{P}$ for the interaction $\geq 0.05$ indicated additive effect, and $\mathrm{P}<0.05$ indicated supraadditive effect. To evaluate the combined effect in SCCVII cells in vitro, the surviving fractions with and without DS2248 were compared between 0 Gy and each dose. In SCCVII tumors, the volume doubling times were calculated for each growth curve and compared.

\section{Results}

\section{In vitro activity}

Figure 2 shows radiation dose-survival curves for SCCVII cells after radiation with or without 24-hour pretreatment with DS-2248. At $50 \mathrm{nM}$, DS-2248 showed mild cytotoxicity (surviving fraction $=0.72 \pm 0.03$ ). When combined with radiation, the cell survival curve was steeper than the curve after radiation alone. The combined effect was considered to be supra-additive ( $\mathrm{P}=0.0001$ at $2 \mathrm{~Gy}$, $<0.0001$ at 4,6 , and 8 Gy by post hoc Tukey's HSD test).

\section{Changes in $\gamma \mathrm{H} 2 \mathrm{AX}$ foci per nucleus}

Figure 3 shows the number of $\gamma \mathrm{H} 2 \mathrm{AX}$ foci in SCCVII cells with etoposide treatment (positive control), without 

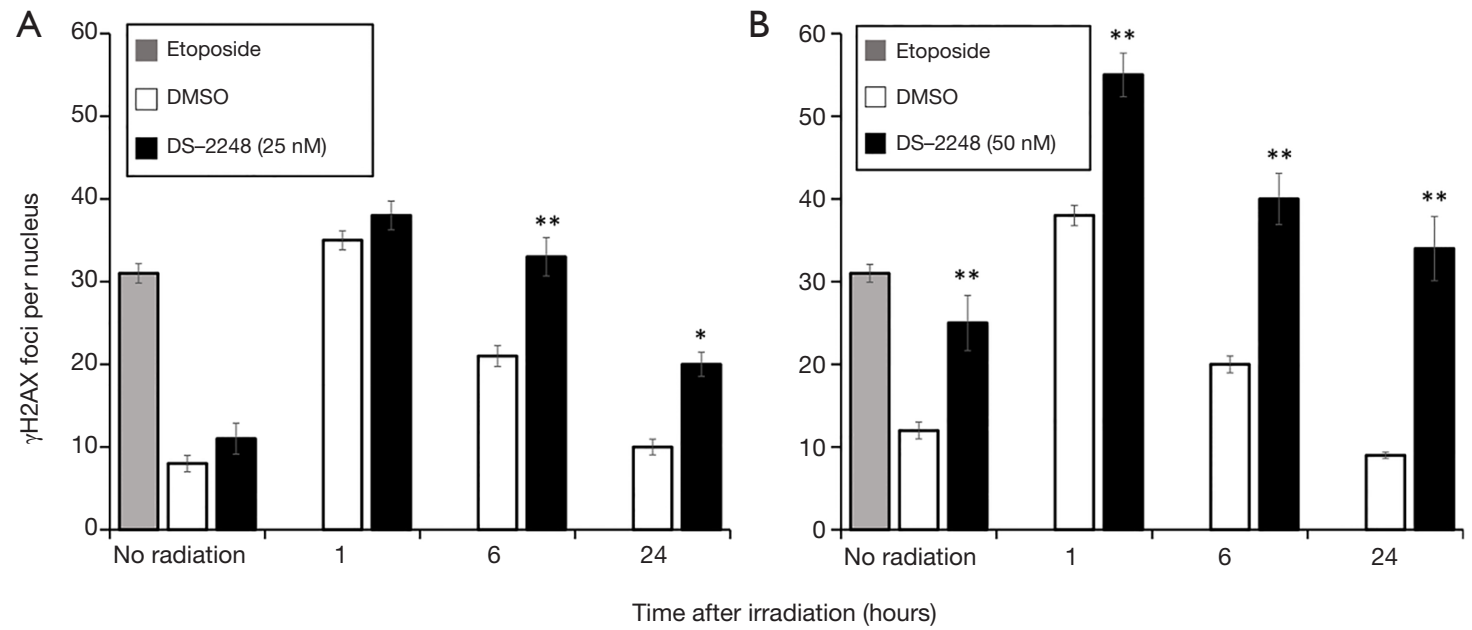

Figure $3 \gamma \mathrm{H} 2 \mathrm{AX}$ foci/nucleus with 24-hour etoposide treatment $(100 \mu \mathrm{M})$ in SCCVII cells, with no radiation, and at 1, 6, and 24 hours after 2-Gy radiation with or without DS-2248 (A: $25 \mathrm{nM}$; B: $50 \mathrm{nM}$ ). Bars represent standard errors of 3 experiments. ${ }^{*} \mathrm{P}=0.002,{ }^{* *} \mathrm{P}<0.001$ between radiation-alone and radiation + DS-2248 groups by $t$-test.

irradiation (DMSO or DS-2248 alone), and at 1, 6, and 24 hours after 2-Gy radiation with or without DS-2248 (25 and $50 \mathrm{nM}$ ). Without irradiation, DS-2248 at both 25 and $50 \mathrm{nM}$ produced more $\gamma \mathrm{H} 2 \mathrm{AX}$ foci compared to the DMSO control. In the DMSO-treated cells, $\gamma \mathrm{H} 2 \mathrm{AX}$ foci numbers were at maximum levels at 1 hour after irradiation, but returned to the levels of unirradiated cells by 24 hours. In contrast, $\gamma \mathrm{H} 2 \mathrm{AX}$ foci remained for longer periods in DS2248 -treated cells. At 1 hour after irradiation, DS-2248 plus 2-Gy irradiation produced more $\gamma \mathrm{H} 2 \mathrm{AX}$ foci than $2 \mathrm{~Gy}$ alone, and this difference became larger at 6 and 24 hours.

\section{Tumor growth delay assay}

Figure $4 \mathrm{~A}$ shows results of the growth delay assay to investigate the effect of DS-2248 at drug doses of 5, 10, and $15 \mathrm{mg} / \mathrm{kg}$ in combination with 24 Gy delivered in 6 fractions. With the dose of $15 \mathrm{mg} / \mathrm{kg}$ administered 10 times, a significant growth delay was observed, whereas with the doses of 5 and $10 \mathrm{mg} / \mathrm{kg}$, the growth delay was minimal or mild. Combined treatment with DS-2248 and radiation produced greater tumor growth delays than radiation alone. The combined effect was considered additive at the DS2248 dose of $5 \mathrm{mg} / \mathrm{kg}$, whereas it was considered supraadditive at 10 and $15 \mathrm{mg} / \mathrm{kg}(\mathrm{P}=0.25$ for $5 \mathrm{mg} / \mathrm{kg},<0.0001$ for $10 \mathrm{mg} / \mathrm{kg}$, and $<0.004$ for $15 \mathrm{mg} / \mathrm{kg}$ by post hoc Tukey's HSD test). Figure $4 B$ shows the changes in the weight of all mice used in this study; no differences were observed between the DS-2248-treated and control mice.
Figure $5 A$ shows results of the growth delay assay to investigate the effect of DS-2248 at a dose of $15 \mathrm{mg} / \mathrm{kg}$ in combination with a total dose of 6,12 , and 18 Gy delivered in 6 fractions. Again, administration of DS-2248 produced substantial growth delays. Combined treatment with DS2248 and radiation produced greater tumor growth delays than radiation alone; the combined effect was considered supra-additive at 12 and $18 \mathrm{~Gy}(\mathrm{P}=0.31$ for $6 \mathrm{~Gy}, 0.046$ for 12 Gy, and $<0.0001$ for 18 Gy by post hoc Tukey's HSD test). Figure $5 B$ shows the changes in the weight of all mice used in this study; no differences were observed between the DS-2248-treated and control mice.

\section{Western blotting}

Figure 6 shows upregulation of HSP70 in SCCVII tumors treated by DS-2248 alone or DS-2248 plus radiation (Lane 5-8), whereas HSP70 was not upregulated by vehicle or vehicle plus radiation.

\section{Discussion}

Among various HSP90 inhibitors developed to date, geldanamycin and its derivative, 17-AAG, have been extensively studied in the laboratory. Radiosensitizing effects of these two compounds have also been studied, and the possibility of the compounds as radiosensitizers was reported (24-26). The mechanism was suggested to be modulation of the balance among 
A

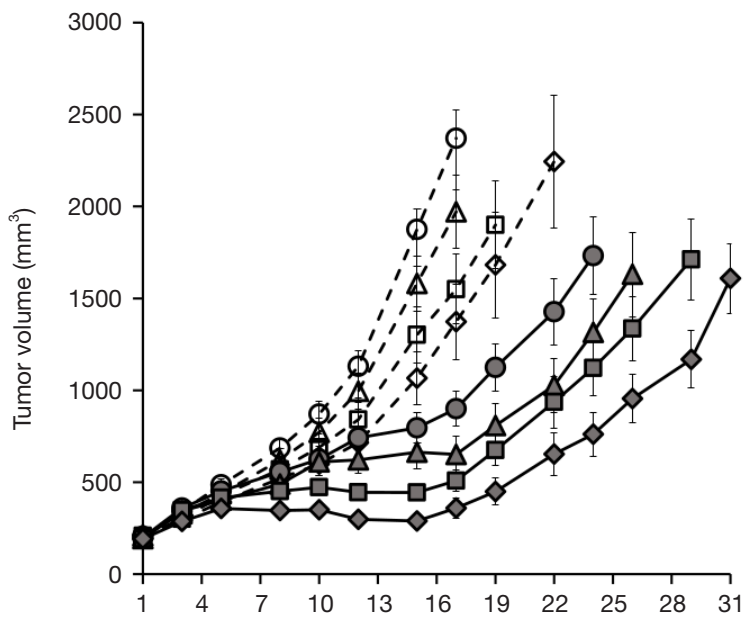

B

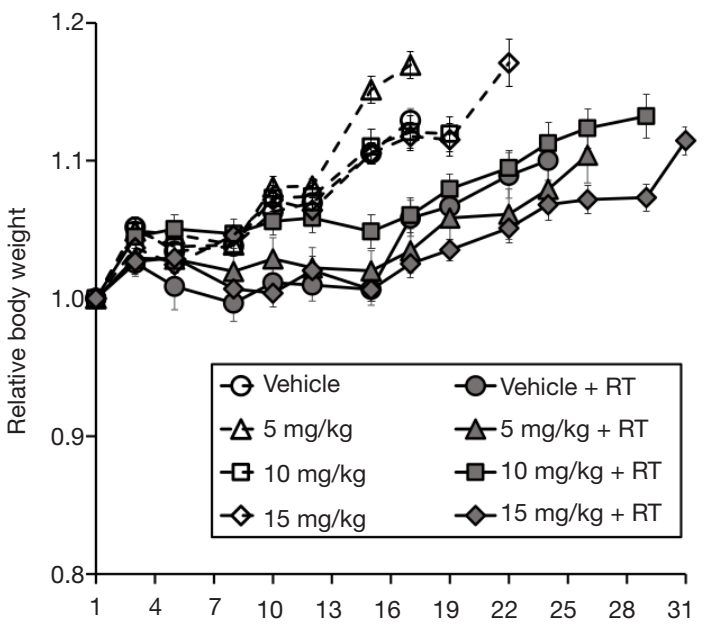

$\uparrow \uparrow \uparrow \uparrow \uparrow \quad \uparrow \uparrow \uparrow \uparrow \uparrow$

R R R R R R

Days after treatment

$\uparrow$ DS-2248 5, 10, $15 \mathrm{mg} / \mathrm{kg} \times 5 / \mathrm{wk} \times 2 \mathrm{wks}$ (p.o.)

Radiation 4 Gy $\times 3 /$ wk $\times 2$ wks (total 24 Gy)

Figure 4 Growth curves for SCCVII tumors (A) and changes in body weight of C3H/HeN mice (B) after administration of vehicle or DS$2248(5,10$, or $15 \mathrm{mg} / \mathrm{kg} \times 10$ times, open symbols) and DS-2248 plus radiation with 24 Gy in 6 fractions (closed symbols). Bars represent standard errors of 12 mice. Regarding whether the combined effect was supra-additive or additive, P was 0.25 for $5 \mathrm{mg} / \mathrm{kg},<0.0001 \mathrm{for}$ $10 \mathrm{mg} / \mathrm{kg}$, and 0.004 for $15 \mathrm{mg} / \mathrm{kg}$ by post hoc Tukey's HSD (honestly significant difference) test.

A

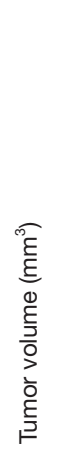

2500
2000
1500
1000
500

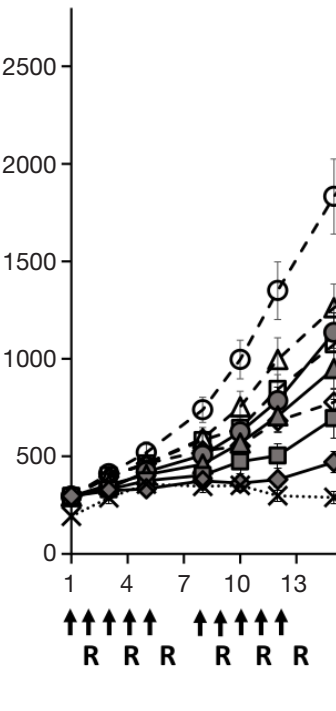

B

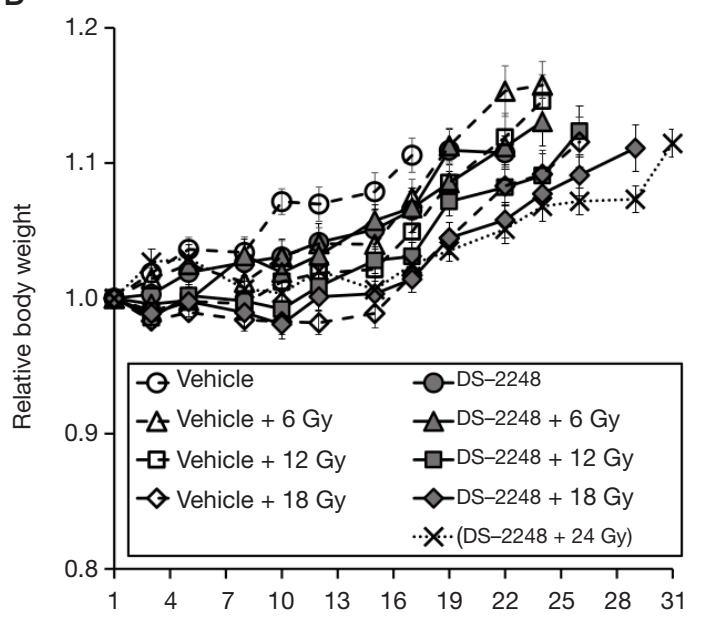

Days after treatment

个 DS-2248 $15 \mathrm{mg} / \mathrm{kg} \times 5 / \mathrm{wk} \times 2 \mathrm{wks}$ (p.o.)

R Radiation 1, 2, 3 Gy $\times 3 /$ wk $\times 2$ wks (total 6,12,18 Gy)

Figure 5 Growth curves for SCCVII tumors (A) and changes in body weight of $\mathrm{C} 3 \mathrm{H} / \mathrm{HeN}$ mice (B) after administration of vehicle or DS$2248(15 \mathrm{mg} / \mathrm{kg} \times 10$ times, open symbols) and DS-2248 plus radiation with 6, 12, or 18 Gy in 6 fractions (closed symbols). Bars represent standard errors of 12 mice. For reference, the curve for $15 \mathrm{mg} / \mathrm{kg}$ DS-2248 +24 Gy in Figure 4 is included. Regarding whether the combined effect was supra-additive or additive, P was 0.31 for 6 Gy, 0.046 for 12 Gy, and $<0.0001$ for 18 Gy by post hoc Tukey's HSD (honestly significant difference) test. 


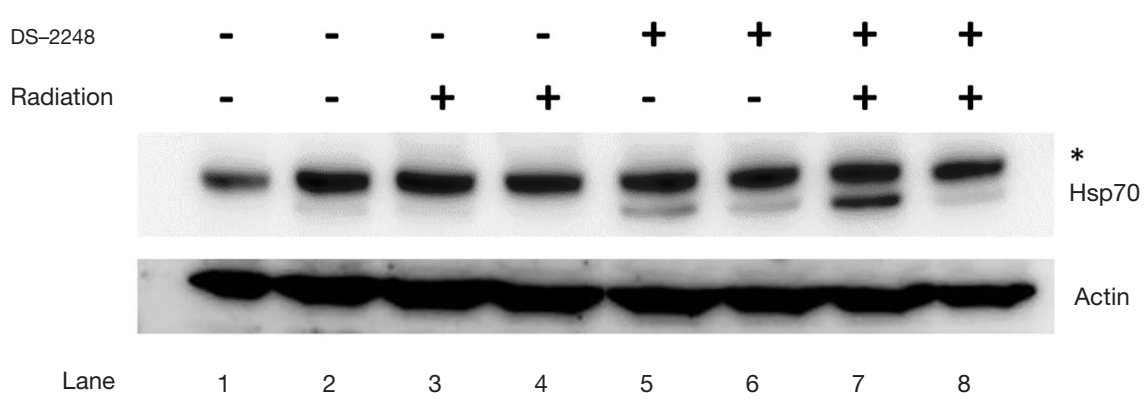

Figure 6 Western blotting for SCCVII tumors in C3H/HeN mice receiving vehicle alone (Lane 1, 2), vehicle + radiation $(4$ Gy $\times 6$ fractions $/ 2$ weeks; Lane 3, 4), DS-2248 alone $(15 \mathrm{mg} / \mathrm{kg} \times 10$ times $/ 2$ weeks; Lane 5, 6), and DS-2248 (15 mg/kg $\times 10$ times/2 weeks) + radiation (4 Gy $\times 6$ fractions/2 weeks; Lane 7,8). *The band above Hsp70 represents near-70-kilodalton proteins, which may be non-specific or specific to SCCVII tumors.

mitogenic, antiproliferative, and apoptotic pathways for geldanamycin (24). More recently, suppression of radiation-induced DNA DSB was reported for an isoxazole resorcinol-based HSP90 inhibitor, NVP-AUY922 (VER52296), and a non-geldanamycin triazolone HSP90 inhibitor, ganetespib $(11,27,28)$. However, combinations of inhibition of cell growth and survival pathways, ubiquitous delay in Rad51-mediated homologous recombination, CHK1-mediated G2/M arrest, and cell cycle perturbation were also considered to be associated with radiosensitization by NVP-AUY922 (11), and HIF-1 $\alpha$-mediated mechanisms of HSP90 inhibition were also suggested for ganetespib (29). In our study, the combination of DS-2248 and radiation produced larger amounts of $\gamma \mathrm{H} 2 \mathrm{AX}$ foci and this may be in part the results of combination of the two DNA-damaging treatments. However, when the $\gamma \mathrm{H} 2 \mathrm{AX}$ foci numbers in the no-radiation groups and those at $24 \mathrm{~h}$ were compared (Figure 3), it seemed that repair of DSB was suppressed in cells treated with radiation + DS-2248 compared to cells receiving radiation alone. This would suggest that inhibition of DNA repair is one of the reasons for the combined effects of radiation and DS-2248. Since the DNA repair was more markedly suppressed at 6 and 24 hours after radiation, inhibition of homologous recombination (slow repair) may be more closely associated than non-homologous end joining; this is in agreement with results of previous studies $(11,30)$, although both proteins associated with homologous recombination and those associated with non-homologous end joining are client proteins of HSP90 $(31,32)$.

Cytotoxic effects of DS-2248 have been previously reported by the developers of this compound; the concentration that inhibited $50 \%$ cell growth with 3 -day
DS-2248 treatment, as assessed using an MTT assay in 4 cell lines, was 9-51 nM. Moreover, DS-2248 induced apoptosis of various types of tumor cells (Honma et al., presented at 7 th International Conference on the Hsp90 Chaperone Machine, Seeon Abbey, Germany, October 15-19, 2014). In the present study, DS-2248 at a concentration of $50 \mathrm{nM}$ appeared to have a mild cytotoxic effect, and this was considered to be due to the relative resistance of SCCVII cells to cytotoxic treatment compared to human tumor cells $(18,33)$; however, it seemed to have synergistic effect with radiation. Based on the in vivo efficacy demonstrated in the present study, more detailed in vitro studies are ongoing in our laboratory, and we did not further investigate the in vitro efficacy in the present study. In our future study, mechanisms of the combined effects and combination with proton beams will be investigated in more detail.

In SCCVII tumors, Western blotting showed upregulation of HSP70 by DS-2248 \pm radiation treatment, so HSP90 was considered to be inhibited in the tumor. The combined effects were observed and these effects appeared to be additive at relatively low doses of DS-2248 (5 and $10 \mathrm{mg} / \mathrm{kg}$ ) and with total radiation doses of 6-18 Gy. The effect was only considered supra-additive when $15 \mathrm{mg} / \mathrm{kg}$ of DS-2248 was combined with a total dose of 24 Gy. Potentiation of the combined effects at high drug and radiation doses is a commonly observed phenomenon both in vitro and in vivo (21), as is also shown in our study (Figure 2). However, the combined effects were never sub-additive and thus, it may be worthwhile to consider concurrent use of this compound and radiation therapy in clinical application. The absence of significant changes 
in body weight of DS-2248-treated compared to DS2248-untreated mice was favorable for DS-2248. A Phase I study of this compound has been completed, and low toxicities have been observed [https://clinicaltrials.gov/ct2/ show/NCT01288430]. To further evaluate the possibility of this compound as a clinically useful anti-cancer and radiosensitizing agent, further laboratory as well as clinical studies are warranted.

As a limitation of this study, only one tumor cell line was employed, so it may be unclear whether the results obtained can be generalized or not. However, SCCVII cells have been employed in many studies of chemical modifiers, and the efficacy of a radiosensitizer was similar among SCCVII tumors and other four human pancreatic cancers (33). In future studies, we plan to test DS-2248 in other tumor models. Another limitation was that other cytotoxicity assays and immunohistochemistry studies of relevant organs were not performed, and these should also be topics of future studies.

In conclusion, potent anti-tumor effects of a new HSP90 inhibitor, DS-2248, were observed when used in combination with radiation in SCCVII cells in vitro and in vivo. The mechanism for this effect is likely to be related to the downregulation of DNA repair after DS-2248 treatment. These results would warrant further clinical investigation of HSP90 inhibitors in combination with radiation therapy.

\section{Acknowledgments}

This study was carried out in part at the Core Laboratory, Nagoya City University Graduate School of Medical Sciences. The authors are grateful to Mr. Hiroshi Takase for technical support and Drs. Shinji Tsutsumi, Satoshi Ishikura, Hiromitsu Iwata, Shingo Hashimoto, Taiki Takaoka, Yasutaka Ogawa, Koichiro Nakajima, and Kento Nomura for valuable discussions during the preparation of this study.

The authors thank Daniel Mrozek for English Proofreading.

Funding: This work was supported in part by JSPS KAKENHI Grant Number 18K07725.

\section{Footnote}

Reporting Checklist: The authors have completed the ARRIVE checklist. Available at https://dx.doi.org/10.21037/ tcr-21-71
Data Sharing Statement: Available at https://dx.doi. org/10.21037/tcr-21-71

Peer Review File: Available at https://dx.doi.org/10.21037/ tcr-21-71

Conflicts of Interest: All authors have completed the ICMJE uniform disclosure form (available at https://dx.doi. org/10.21037/tcr-21-71). Except Koichi Nakamura and Masayuki Matsuo (from Daiichi-Sankyo Co., Ltd.), all other authors report grants from JSPS KAKENHI, during the conduct of the study.

Ethical Statement: The authors are accountable for all aspects of the work in ensuring that questions related to the accuracy or integrity of any part of the work are appropriately investigated and resolved. All animal experiments were performed under a project license (NO.: H29M-09) granted by the Animal Ethics Committee of Nagoya City University, in compliance with Japanese Fundamental Guidelines for Proper Conduct of Animal Experiment and Related Activities in Academic Research.

Open Access Statement: This is an Open Access article distributed in accordance with the Creative Commons Attribution-NonCommercial-NoDerivs 4.0 International License (CC BY-NC-ND 4.0), which permits the noncommercial replication and distribution of the article with the strict proviso that no changes or edits are made and the original work is properly cited (including links to both the formal publication through the relevant DOI and the license). See: https://creativecommons.org/licenses/by-nc-nd/4.0/.

\section{References}

1. Patel HJ, Modi S, Chiosis G, et al. Advances in the discovery and development of heat-shock protein 90 inhibitors for cancer treatment. Expert Opin Drug Discov 2011;6:559-87.

2. Solárová Z, Mojžǐ̌ J, Solár P. Hsp90 inhibitor as a sensitizer of cancer cells to different therapies (Review). Int J Oncol 2015;46:907-26.

3. Shah S, Luke JJ, Jacene HA, et al. Results from phase II trial of HSP90 inhibitor, STA-9090 (ganetespib), in metastatic uveal melanoma. Melanoma Res 2018;28:605-10.

4. Piotrowska Z, Costa DB, Oxnard GR, et al. Activity of the Hsp90 inhibitor luminespib among non-small-cell lung cancers harboring EGFR exon 20 insertions. Ann Oncol 
2018;29:2092-7.

5. Goyal L, Chaudhary SP, Kwak EL, et al. A phase 2 clinical trial of the heat shock protein 90 (HSP 90) inhibitor ganetespib in patients with refractory advanced esophagogastric cancer. Invest New Drugs 2020;38:1533-9.

6. Hoter A, El-Sabban ME, Naim HY. The HSP90 family: structure, regulation, function, and implications in health and disease. Int J Mol Sci 2018;19:2560.

7. Whitesell L, Lindquist SL. HSP90 and the chaperoning of cancer. Nat Rev Cancer 2005;5:761-72.

8. McClellan AJ, Xia Y, Deutschbauer AM, et al. Diverse cellular functions of the Hsp90 molecular chaperone uncovered using systems approaches. Cell 2007;131:121-35.

9. Spiegelberg D, Abramenkovs A, Mortensen ACL, et al. The HSP90 inhibitor Onalespib exerts synergistic anticancer effects when combined with radiotherapy: an in vitro and in vivo approach. Sci Rep 2020;10:5923.

10. Camphausen K, Tofilon PJ. Combining radiation and molecular targeting in cancer therapy. Cancer Biol Ther 2004;3:247-50.

11. Ha K, Fiskus W, Rao R, et al. Hsp90 inhibitor-mediated disruption of chaperone association of ATR with hsp90 sensitizes cancer cells to DNA damage. Mol Cancer Ther 2011;10:1194-206.

12. Zaidi S, McLaughlin M, Bhide SA, et al. The HSP90 inhibitor NVP-AUY922 radiosensitizes by abrogation of homologous recombination resulting in mitotic entry with unresolved DNA damage. PLoS One 2012;7:e35436.

13. Garcia-Carbonero R, Carnero A, Paz-Ares L. Inhibition of HSP90 molecular chaperones: moving into the clinic. Lancet Oncol 2013;14:e358-69.

14. Pacey S, Wilson RH, Walton M, et al. A phase I study of the heat shock protein 90 inhibitor alvespimycin (17DMAG) given intravenously to patients with advanced solid tumors. Clin Cancer Res 2011;17:1561-70.

15. Sequist LV, Gettinger S, Senzer NN, et al. Activity of IPI504, a novel heat-shock protein 90 inhibitor, in patients with molecularly defined non-small-cell lung cancer. J Clin Oncol 2010;28:4953-60.

16. Ohki H, Okayama T, Ikeda $M$, et al. Tricyclic pyrazolopyrimidine derivative. United States Patent Application Publication, 2012:US2012/0202833 A1.

17. Shibamoto $Y$, Yukawa $Y$, Tsutsui $\mathrm{K}$, et al. Variation in the hypoxic fraction among mouse tumors of different types, sizes, and sites. Jpn J Cancer Res 1986;77:908-15.

18. Shibamoto Y, Streffer C, Fuhrmann C, et al. Tumor radiosensitivity prediction by the cytokinesis-block micronucleus assay. Radiat Res 1991;128:293-300.

19. Shibamoto $Y$, Ito $M$, Sugie C, et al. Recovery from sublethal damage during intermittent exposures in cultured tumor cells: implications for dose modification in radiosurgery and IMRT. Int J Radiat Oncol Biol Phys 2004;59:1484-90.

20. Wang Z, Sugie C, Nakashima M, et al. Changes in the proliferation rate, clonogenicity, and radiosensitivity of cultured cells during and after continuous low-dose-rate irradiation. Dose Response 2019;17:1559325819842733.

21. Shibamoto Y, Murata R, Miyauchi S, et al. Combined effects of clinically relevant doses of emitefur, a new 5 -fluorouracil derivative, and radiation in murine tumors. Br J Cancer 1996;74:1709-13.

22. Takaoka T, Shibamoto Y, Matsuo M, et al. Biological effects of hydrogen peroxide administered intratumorally with or without irradiation in murine tumors. Cancer Sci 2017;108:1787-92.

23. Shibamoto Y, Miyauchi S, Kiyokawa H, et al. Oral vehicle administration before radiation causes radioprotection of murine SCCVII tumors. Oncol Rep 1997;4:787-9.

24. Matsumoto Y, Machida H, Kubota N. Preferential sensitization of tumor cells to radiation by heat shock protein 90 inhibitor geldanamycin. J Radiat Res 2005;46:215-21.

25. Noguchi M, Yu D, Hirayama R, et al. Inhibition of homologous recombination repair in irradiated tumor cells pretreated with Hsp90 inhibitor 17-allylamino-17demethoxygeldanamycin. Biochem Biophys Res Commun 2006;351:658-63.

26. Fujii Y, Kato T, Kubota N, et al. p53 independent radiosensitization of human lymphoblastoid cell lines by Hsp90 inhibitor 17-allylamino-17-demethoxygeldanamycin. Oncol Rep 2010;23:199-203.

27. Chettiar ST, Malek R, Annadanam A, et al. Ganetespib radiosensitization for liver cancer therapy. Cancer Biol Ther 2016;17:457-66.

28. Kühnel A, Schilling D, Combs SE, et al. Radiosensitization of HSF-1 knockdown lung cancer cells by low concentrations of Hsp90 inhibitor NVP-AUY922. Cells 2019;8:1166.

29. Nagaraju GP, Zakka KM, Landry JC, et al. Inhibition of HSP90 overcomes resistance to chemotherapy and radiotherapy in pancreatic cancer. Int J Cancer 2019;145:1529-37.

30. IJff M, van Oorschot B, Oei AL, et al. Enhancement of radiation effectiveness in cervical cancer cells by 
combining ionizing radiation with hyperthermia and molecular targeting agents. Int J Mol Sci 2018;19:2420.

31. Pennisi R, Ascenzi P, di Masi A. Hsp90: A new player in DNA repair? Biomolecules 2015;5:2589-618.

32. Hirakawa H, Fujisawa H, Masaoka A, et al. The combination of Hsp90 inhibitor 17AAG and heavy-ion

Cite this article as: Kondo T, Shibamoto Y, Kawai T, Sugie C, Wang Z, Nakamura K, Murai T, Manabe Y, Nakashima M, Matsuo M. Effects of a combined treatment regimen consisting of Hsp90 inhibitor DS-2248 and radiation in vitro and in a tumor mouse model. Transl Cancer Res 2021;10(6):2767-2776. doi: $10.21037 /$ tcr-21-71 irradiation provides effective tumor control in human lung cancer cells. Cancer Med 2015;4:426-36.

33. Shibamoto Y, Kubota T, Kishii K, et al. Radiosensitivity of human pancreatic cancer cells in vitro and in vivo, and the effect of a new hypoxic cell sensitizer, doranidazole. Radiother Oncol 2000;56:265-70. 